\title{
Sus cuerpos, nuestras vidas: torso desnudo y mandil en la historia mixteca de la costa
}

Koño ñu'u ñu cha ndyto cha nda'a: ndii chata tya sa'ma cha ndasi ndyika ñiui chiñuu cha iyo ñuu yu'u ndutya nuú ${ }^{l}$ Their Bodied, Our Lives: From Toplessness to
Aprons in Coastal Mixteca History

Seus corpos, nossas vidas: torso nu e avental na história da costa Mixteca

\author{
Liliana María Gómez Montes \\ Profesora e investigadora \\ Universidad del Mar, Campus Huatulco \\ México \\ Recibido: 11/4/2016 Aceptado: 6/6/2016 \\ DOI: http://dx.doi.org/10.15359/tdn a.32-60.6

\section{Resumen} \\ En la región costera de Oaxaca, en Méxi- \\ $\mathrm{co}$, hay diversos pueblos mixtecos que nos \\ cuentan algo de su historia a través de sus \\ formas de vestir. Hoy en día podemos \\ encontrar en algunas de sus comunida- \\ des que las mujeres usan su pozahuanco \\ (falda de algodón local, a rayas). Unas \\ llevan el torso desnudo, otras lo han \\ cubierto con un mandil de tela \\ de algodón industrial. A través \\ de entrevistas con las mujeres \\ mayores del lugar he ido
} reconstruyendo su memoria colectiva acerca

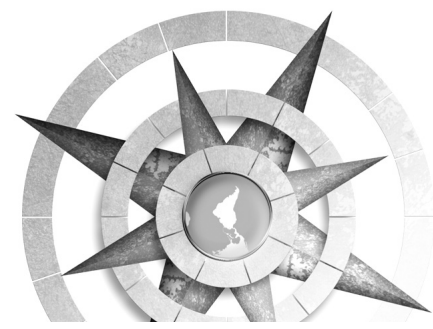

del proceso de taparse el torso con el mandil. ¿Cómo, cuándo, por qué, quiénes fueron los primeros en llegar a mediados del siglo XX generando evidentes cambios en las formas de expresar su vestir y su desnudez? Haré una lectura historiográfica acerca del proceso de cambio en sus expresiones corporales.

Palabras clave: mujeres mixtecas, desnudo femenino, indigenismo, mandil, pozahuanco, Temas de Nuestra América

\section{Abstract}

The coastal region of Oaxaca, Mexico, is home to several Mixtec populations who tell of their history through their clothing. Today, there are several communities in which the women wear pozahuancos (a

\footnotetext{
N.E.: Título en lengua mixteca, gracias a la colaboración de la Sra. Ynocencia Simón, maestra normalista bilingüe
} 
striped skirt made from locally-grown cotton). Some go topless, while others cover themselves with a cotton apron. Through interviews with the elderly women of the community, we have reconstructed their collective memory of how they came to cover themselves with an apron. How, when, why and who were the first to arrive in the mid-20th century, generating obvious changes in the ways of expressing their dress and nudity. This work provides a historiography of the process of change in their body expressions.

Keywords: mixtec women, female nakedness, indigenism, aprons, indigenous, women's clothing, Temas de Nuestra América

\section{Resumo}

A região costeira de Oaxaca, no México, é o lar de várias populações mixtecas que contam a sua história através de suas roupas. Hoje, existem várias comunidades em que as mulheres usam pozahuancos (uma saia listrada de algodão cultivados localmente). Algumas vão topless, enquanto outras poderão cobrir com um avental de algodão. Mediante entrevistas com as mulheres idosas da comunidade, reconstruímos sua memória coletiva de como eles chegaram a cobrir-se com um avental. Como, quando, por que e quem foram os primeiros a chegar em meados do século 20, gerando mudanças óbvias nas formas de expressar seu vestido e seu nudez. Este trabalho fornece uma historiografia do processo de mudança em suas expressões corporais.

Palavras chave: mulheres mixtecas, nu feminino, indigenismo, avental, roupas mulheres indianas, Temas de Nuestra América
En México, en la costa de Oaxaca, encontramos comunidades mixtecas que entrelazan tradiciones ancestrales con la modernidad. Cuando visité algunas de sus comunidades, como Huaxpaltepec, Pinotepa de Don Luis, Mechoacán y Chayuco, por primera vez entre 2014 y 2015, me llamó la atención que había señoras con su torso desnudo barriendo frente a la puerta de su casa. Era evidente que su desnudez era algo cotidiano para sus vecinos, pues a nadie le llamaba la atención en particular que así fuera.

Estaba alojada con mis estudiantes universitarios en su casa familiar en Huaxpaltepec. Ellos vestían con sus pantalones de mezclilla, como lo hacen todos los días de su vida universitaria. Su mamá, que es una maestra bilingüe de primaria, siempre usa pantalones de algodón hasta la pantorrilla y una blusa hasta la cadera. Mientras estuve en su casa otras señoras del pueblo llegaron a comprar tortillas hechas a mano, venían cubiertas con un mandil de tela hecha en fábrica. Todas las mujeres que vi durante el día, fuera de torso desnudo o usando un mandil, llevaban como falda un lienzo de algodón pesado, elaborado en un telar de cintura. A esta falda la llaman pozahuanco o che'e.

Mi mirada denotaría extrañeza y un gran aprecio por las formas culturales 
tan diversas e inesperadas. Siempre discreta y respetuosa, estaba sorprendida ante las naturales expresiones de vivir su cuerpo. Observé fotos antiguas, pregunté sobre sus costumbres y me percaté de que el mandil había llegado apenas a mediados del siglo XX, como una prenda que cumpliría la función de cubrir la costumbre del torso expuesto al sol.

Me surgieron muchas preguntas y desarrollé un proyecto de investigación con el apoyo de la Universidad del Mar, mis estudiantes y su familia, quienes me alojaron en su casa durante el proceso de investigación.

Al buscar información respecto a estas formas de vestir de las mixtecas, me encontré con que esta es una investigación original, ya que no se había trabajado en la región con preguntas acerca del mandil y de los torsos descubiertos. Hay algunas referencias antropológicas y monográficas que dan un testimonio de estos cuerpos durante la mitad del siglo XX.

De Alfonso Fabila, un antropólogo que llegó como colaborador del Centro Coordinador Indigenista de Jamiltepec, a cargo del Instituto Nacional Indigenista, en 1957, tenemos un trabajo monográfico sobre los mixtecos.

También tenemos a Gutierre Tibón, un escritor ítalomexicano que combinaría intereses literarios y antropológicos; hará un viaje por aquellos pueblos y a manera de diario nos contará algunas de sus anécdotas. El fotógrafo Mario Mutschlechner, quien visitó la zona en los años sesenta, treinta años después, publicaría sus fotografías a través de una mirada poética y erótica. Además, tenemos un trabajo antropológico de Susana Drucker en el que se reflexiona acerca de algunos casos de abandono de la vestimenta tradicional en Jamiltepec en el que las mujeres cambiarían su ropa tradicional por un vestido específico de la época.

Alfonso Fabila apenas trata el tema del vestido y el torso desnudo a lo largo de la monografía que escribió en 1957, aunque hace una referencia muy valiosa: «El vestido tradicional mixteco es hermoso y nos parece adecuado al clima, pero tal vez los urbanistas lo juzguen deficiente porque las mujeres llevan en sus casas el busto completamente desnudo y los niños muchas veces andan sin ropa» (Fabila, 2010, p. 50). Interesantes los términos que encontró el antropólogo para mostrar su asombro ante la desnudez de aquellas mujeres. Dice que «los urbanistas» se sentirían extrañados, sin definirse él mismo como tal, cuando también venía de la ciudad. Y el adjetivo «deficiente» nos muestra un término pudoroso para señalar que algo les faltaba. 
Por su parte el escritor ítalomexicano Gutierre Tibón en 1961 visita estas comunidades, llegando en avioneta y recorriéndolas a caballo. La carretera estaría terminada hasta 1968 . Su texto está lleno de emociones desde su llegada. Cuenta que se siente aceptado por los lugareños y señala la denominación de nucoyo, con la que los mixtecos se refieren a los visitantes. Entonces como ahora se empleaban los términos de gente de costumbre y gente de razón para distinguirse entre los originarios y los no indígenas. Marcando una evidente jerarquización verbal con la que se excluiría la voz del otro, descalificándolo, pues aparentemente le faltaría razón.

Cuando Gutierre Tibón observa la costumbre del torso desnudo de las jóvenes mixtecas así lo relata:

Al llegar a la orilla de Jicaltepec vi a una muchacha desnuda, que se bañaba en un manantial rodeado de helechos y musgo, una de las fuentes que abundan en el pueblo. No había ningún otro ser humano en los alrededores.

-¿Dónde está el templo? -pregunté torpemente, desde lo alto de mi caballo. Confieso que me faltó un poco el aliento. Nunca me pareció más lindo el color de una piel. Me miró con perfecta tranquilidad, y soltó con voz de pajarito un largo discurso mixteco, que no entendí (1961, pp. 22-23).
El escritor da testimonio de esta costumbre y manifiesta su asombro, configurándolo en un contexto de paraíso natural, en el que se baña un cuerpo joven y desnudo, con la misma transparencia del agua del manantial. Es pertinente señalar que en la elaboración de la pregunta que este autor hizo a esta joven lo que vino a su mente fue el «templo», es decir la Iglesia, la constructora de una ideología moral que cubre el cuerpo, aspecto que no pasa desapercibido ni para este autor, que añadirá renglones más adelante que las condiciones de calor bien justificarían el torso desnudo. Se hace explícito el respeto. Los cuerpos se imponen a partir de una ética de la presencia, que expresa el mundo al que pertenecen como seres colectivos, tanto para el que está tapado como para la que está desnuda.

Por otra parte, Mario Mutschlechner nos deja su testimonio fotográfico (1968 y 1969). Llegó muy joven a la región y tomó sus fotos, guardándolas por treinta años, hasta que encontró el momento de su publicación, apenas en el 2002. En la presentación de sus documentos fotográficos armados en un libro representa, como todos los visitantes externos a estas comunidades, la sorpresa por la expresión inesperada de estos cuerpos de mujeres que han vivido sus pechos al aire, manifestando ligereza y naturalidad. A las fotos

110 Sus cuerpos, nuestras vidas: torso desnudo y mandil... Liliana María Gómez Montes 
les incluirá poesía y referencias históricas antiguas, dando en su lectura un ambiente de suave sensualidad. Reconocerá, como todos lo hemos hecho, la necesidad de dar una mirada respetuosa ante nuestra diferencia cultural.

Es indudable que somos rotundamente corpóreos y materiales. Que nuestros cuerpos transmiten los códigos de nuestra comunidad, configurando un lenguaje que comunica la memoria de nuestro contexto histórico. Podemos observar que la mirada sobre los cuerpos que se manifiestan los reinventa y resignifica, como lo hace el fotógrafo, recordándonos que somos sociales, dinámicos y que no hay una sola manera de observar una situación. Que la mirada toma y da, descubre e inventa. En este caso, las mujeres de las fotos son las mismas y a la vez son otras, por la poética erótica que las enmarca, dándoles un atributo que no tenían antes de ser fotografiadas.

En 1963 la antropóloga estadounidense Susana Drucker desarrolló su trabajo en el pueblo de Jamiltepec, observando el tema de la vestimenta o del revestimiento, como ella le llama al cambio de indumentaria. Su enfoque se centró en la adopción del vestido y el abandono del textil de elaboración propia, a través del que se expresarían «las relaciones entre indígenas y mestizos en Jamiltepec [que serían] esencialmente hostiles [pues los] mestizos se consideraban superiores a los mixtecos» (Drucker, 1963, p. 121). La situación era distinta a la actual en cuanto a la aceptación y el rechazo de estos cambios identitarios a través del vestir. En aquel entonces comenzaba un cambio regional, la llegada de gente de fuera que estaría entrando a sus comunidades más cercanas por la carretera, cada vez con mayor frecuencia, lo que iría impactando en sus expresiones culturales, como sucedió con la vestimenta. Pero así como algunas mujeres quisieron amestizarse, un gran grupo de mixtecas continuaron con sus tradiciones textiles hasta la actualidad.

Hemos reconocido que somos cuerpo, que nuestra condición humana se expresa a través de esta concreción y que la vestimenta responde a códigos sociales identitarios: es relevante mostrar esta realidad en un trabajo sobre las culturas. Los escritores anteriores o este fotógrafo, quienes presentan su trabajo sobre las mixtecas de la costa, no pueden escapar a la subjetividad de su mirada, que también es cultural, histórica y a su vez personal. Es fácil encontrarla en sus trabajos, tal como sucede en esta misma investigación.

Actualmente observamos que estas comunidades siguen siendo heterogéneas a su interior, pues en parte 
preservan tradiciones y en parte buscan la novedad y el cambio. Aunque el momento de este estudio es muy distinto al de Drucker, porque en más de cincuenta años las influencias externas no se han detenido. La antropóloga tenía razón cuando imaginaba el futuro inmediato, en el que cada vez habría un número mayor de indígenas que se revestirian como mestizos y que ello no significaría lograr un cambio de su estatus, lo cual había venido siendo uno de los motivadores para el cambio. El renunciar a su mundo indígena y querer adoptar las formas, conocimientos y modos de organización de los mestizos ya no sería garantía de tener un mejor trabajo, un mejor salario o un mayor prestigio.

Así se muestra el panorama textual contemporáneo, en el que se comienza a dar cuenta de estos cuerpos con expresiones de desnudez, sin pena y con naturalidad, de las mujeres mixtecas. Aquellos viajeros que, como yo, se percataron a través del espejeo de la cultura con la que conformamos nuestras lecturas sobre lo social y lo humano que a través de nuestra vestimenta, que cubre poco o mucho nuestro cuerpo, expresamos los códigos culturales que nos contienen, y con ellos hemos configurado nuestro testimonio desde nuestras disciplinas. Constatamos que nuestros aprendizajes se materializan en la forma en que vivimos el cuerpo, pues ante todo es la concreción de nuestra dinámica social con la que nos relacionamos.

Los trabajos anteriores, como los de Fabila, Tibón, Mutschlechner o Ducker, coinciden en el tiempo, todos pertenecen a la mitad del siglo XX. Para entonces apenas irían llegando el Instituto Nacional Indigenista (INI), los viajeros, así como el mandil, que ahora las cubre a muchas de ellas. Por lo que a través de mi investigación habría de responderme ¿cómo comprender la preservación de la costumbre del torso desnudo hasta el 2015? ¿Cuándo, cómo y por qué lo cambiaron por un mandil?

Para recoger información respecto a este proceso histórico cultural se entrevistó a mujeres mayores de cincuenta años (treinta entrevistas), se les preguntó acerca de sus recuerdos sobre la costumbre de usar el pozahuanco con su torso desnudo y cómo fue la introducción del uso del mandil. Nos hablaron de cómo había sido para ellas, para sus madres y para sus hijas. También entrevistamos a algunos hombres mayores de cincuenta años (diez entrevistas), pues queríamos saber también cómo observaban ellos este mismo proceso en las mujeres de su comunidad.

Trabajamos en este proyecto en los pueblos de Huaxpaletepec, Mechoacán, Pinotepa de Don Luis y Chayuco. 
Mis dos estudiantes originarios de Huaxpaltepec realizaron su Servicio Social conmigo para apoyar esta investigación. Su mamá, la señora Ynocencia Simón, maestra normalista bilingüe, fue la llave para acceder a estas mujeres. Desde el comienzo se mostró muy interesada y su colaboración fue fundamental. Con ella logré llegar a las casas de las mujeres entrevistadas, tener su confianza y que mis preguntas fueran traducidas al mixteco, pues muchas de las mujeres eran monolingües.

El dominio de la lengua fue la otra llave maestra para llegar a ellas y lograr escuchar su valioso testimonio. Las fotografiamos, las grabamos y transcribimos sus relatos. También mis estudiantes respondieron el cuestionario, aportando puntos de vista muy interesantes.

Para ampliar la perspectiva sobre este tema también consulté los archivos del Centro Coordinador del INI, que se asentó en Jamiltepec desde mediados del siglo XX. Me pareció interesante encontrar algunas referencias del proyecto de costura y que en ningún escrito se hiciera mención de la desnudez y sus costumbres de sobrellevarla. Tal vez haya algunos otros documentos de esta institución que sí lo hagan y yo no los revisé en estas visitas al archivo, pues me limité solo a aquellos que se relacionaban con los talleres y prácticas aledaños a esta actividad.
Es de esta forma como se configura este texto desde una mirada historiográfica que se nutre de la voz de los habitantes de estas comunidades, así como del archivo del Centro Coordinador del entonces INI, el cual se encontraba resguardado por el Instituto Nacional de Antropología e Historia (INAH) en el antiguo convento de Yanhuitlán.

El contexto histórico de México y de sus políticas indigenistas es una ventana para la comprensión de las condiciones que se vivieron en la mixteca de la costa a mediados del siglo XX. El periodo entre 1940 y 1964 es un momento de promesas económicas para México. Durante las guerras de Europa de los años cincuenta la economía mexicana se vio dinamizada por su crecimiento industrial.

Con el presidente Ávila Camacho (1940-1946) se había iniciado la consolidación del mercado interno y más adelante se continuaría con la idea de un desarrollo estabilizador que habría de poner a México dentro de los países con economías más eficientes dentro del contexto de América Latina. La mitad del siglo XX es un momento de discursos posrevolucionarios y de una industrialización que se desarrolla de manera dependiente dentro de un espejismo de crecimiento acelerado.

Con el presidente Miguel Alemán Valdés (1946-1952) será más evidente 
el inicio del lastimoso periodo en el que los gobernantes se enriquecerán a costa de los recursos de la nación y sus políticas tendrán poco compromiso social. México se encontrará inmerso en los discursos sobre avances y modernidad, que fueron dejando atrás los sueños y compromisos de la Revolución mexicana de 1910. Los discursos políticos hablarán de la incorporación de los grupos olvidados y empobrecidos, como los indígenas, materializándose por ejemplo en la publicación del 4 de diciembre de 1948 en el Diario Oficial de la Federación, en el que se anunciaría la ley que creó el Instituto Nacional Indigenista (INI). Su primer director a nivel nacional será el arqueólogo Alfonso Caso y su vicedirector será el Dr. Gonzalo Aguirre Beltrán. Esta institución surgió como filial del Instituto Indigenista Interamericano y tuvo personalidad jurídica propia. Sus fundadores fueron el arqueólogo $\mathrm{Al}$ fonso Caso Andrade, el Dr. Gonzalo Aguirre Beltrán y el también distinguido arqueólogo Julio de la Fuente.

Con Adolfo Ruiz Cortines, el presidente en turno entre los años de 1952 y 1958, se desarrollaría el Proyecto $\mathrm{Na}$ cional Marcha hacia el mar. El ejecutivo estaría interesado en vincular la economía de una manera más dinámica con el gran litoral que posee México. Se reconocía el poco aprovechamiento del recurso marítimo, así como la desconexión entre la ciudad de México, su política centralista y los pobladores mareños. Los alcances de este proyecto fueron muy limitados, sería más grande el discurso que sus logros, pero se justificarían las cada vez más frecuentes visitas a los distintos pueblos de la costa oaxaqueña.

Al fundarse el INI se anunciaría la creación de esta institución como el inicio de una era para el progreso de las regiones indígenas. Entre sus objetivos iniciales estaría el investigar y desarrollar proyectos en beneficio de la población indígena, asesorar y capacitar instituciones, así como coordinar organismos gubernamentales que trabajarán con fines semejantes a los del INI. El primer Centro Coordinador Indigenista (CCI), que sería el brazo del INI a nivel regional, se instaló en San Cristóbal de las Casas en 1951, mientras en la parte costera de Oaxaca, en Jamiltepec, por decreto presidencial fue hasta 1954. Para entonces se instalarían tres más en la Mixteca Alta.

En ese año los Centros Coordinadores en el Estado de Oaxaca querían unir la Mixteca Alta con la costa, impulsando sus cuatro centros: Tlaxiaco, el Papaloapan, Huautla de Jiménez, dentro de la zona Alta, y el pueblo de Jamiltepec para la región costa. Este último abarcaría con sus servicios 
además de Jamiltepec, los distritos de Putla y Juquila. En el CCI de Jamiltepec se atendería a los chatinos, los amuzgos, los mixtecos, los mestizos y a los afrodescendientes. El mayor número de pobladores de la región eran los mixtecos, y los afrodescendientes, como ahora, una minoría.

Para este momento los académicos mexicanos ya venían desarrollando su propio discurso sobre los temas indígenas. Manuel Gamio fue el primero que profesionalizó el quehacer del antropólogo, fundando en 1911 la Escuela Internacional de Arqueología y Etnología Americana. En su momento aún existía el discurso sobre las razas, en las que aparecían los indígenas como una de ellas. Algo innovador fue que con Gamio se incorporó el concepto de cultura al estudio de los pueblos indígenas, ampliando el concepto sobre las comunidades y sus prácticas. Así se empezó a hablar sobre la cultura de los indios como un cúmulo de creencias y costumbres específicas que por lo menos comenzaban a ser enunciadas en los discursos oficiales y profesionales como algo a lo que se le reconocía su existencia, pues antes habían sido imperceptibles en las políticas federales. Pero esto no iba más allá de la academia y ciertos decretos oficiales, pues en el programa general del Estado y de las instituciones de educación superior se tenía como idea dominante la construcción de una nación moderna y homogénea, en la que lo indio era un problema que debía transformarse y asimilarse a los intereses nacionales. Los indígenas no alcanzaban aún su categoría de sujetos, ciudadanos, diversos, con derechos. Hasta entonces no se escucharía el parecer de los indígenas. Incluso podía considerarse, sin ningún pudor, que estos no tenían algo valioso que decir a la nación, pues, como aún se repite en la región de la costa, la gente de razón es la otra, ellos, los indígenas, solo serían gente de costumbre a su parecer.

Excepcionalmente durante los años treinta se habían asomado algunas ideas de inspiración marxista: «Se propuso fugazmente una alternativa distinta que implicaba un cambio importante en el modelo de país (...) que planteaba que el desarrollo evolutivo de los pueblos podía acelerase mediante el fortalecimiento de sus tendencias a constituir nacionalidades propias» (Warman, 1978, p. 9). Pero estas posturas rápidamente fueron extintas.

Siguieron vigentes por muchos años las ideas sobre el racismo (aún hoy en día no se han logrado erradicar del todo), y a su vez se verían incorporadas algunas ideas culturalistas que proponían que cada pueblo tenía algo original y digno de ser estudiado por 
los especialistas bajo esta nueva mirada, por lo que los antropólogos empezaron a realizar monografías sobre los mismos. Contexto al que pertenecen los primeros estudiosos que llegaron a Jamiltepec, a los que ya me he referido.

También se desarrolló una especie de compromiso moral con los indígenas, a partir del cual se vio el despliegue de «un grupo de especialistas que se concebían como una nueva variedad de apóstoles al servicio del Estado, [y el] Indigenismo» (Warman, 1978, p. 9). La antropología norteamericana fue muy dinámica en este tiempo, pues el mayor número de investigaciones se financiaron por las escuelas estadounidenses. Susana Drucker sería uno de los ejemplos de este momento.

Dentro de este contexto Alfonso Caso será una figura dominante en su época, tanto para el desarrollo de los temas indigenistas como para su aplicación en políticas de Estado. Cuando desaparece el Departamento de Asuntos Indígenas, que tenía la relevancia de una Secretaría de Estado, y se sustituye por un programa en la SEP, este arqueólogo será uno de los principales ejecutores, estando al frente de la formación del Instituto Nacional Indigenista (INI).

El criterio culturalista de Gamio suavizaría las formas de aproximación de los estudios étnicos, pero por el momento las monografías se reducirían a un mero instrumento de clasificación, de aspectos culturales aislados del contexto histórico en el que se estarían expresando y reproduciendo (Warman, 1978). En el fondo no hay un cambio real para los indígenas, pues predomina la idea de extinguirlos como grupo cultural, asimilándolos a lo que llamarán mestizaje, dando lugar, una vez más, a un discurso donde solo existe el indio muerto. Pero la resistencia indígena no se dejará vencer en estos momentos y paradójicamente los idiomas seguirán vivos y reproduciéndose, así como sus textiles. Habrá lenguas con mayor vigor que otras y la mixteca es una de las de mayor fortaleza. Incluso ahora en el siglo XXI podemos constatar el lugar relevante que preserva dentro del patrimonio de las lenguas vivas. En las comunidades incluidas en este estudio fue frecuente encontrar hablantes del mixteco, habiendo incluso mujeres monolingües.

Paralelamente a estos proyectos gubernamentales en los que Caso habrá sido uno de sus protagonistas destacados, surge una postura teórica estable y vigorosa, con una metodología que parte de una visión más amplia de la sociedad y a su vez se arraiga en el conocimiento de las comunidades. Los protagonistas de la buena investigación serán Julio de la Fuente y, de manera 
muy destacada, Gonzalo Aguirre Beltrán, quienes también estarán formando parte de los proyectos del INI y serán parte del equipo que atenderá algunos de los proyectos dentro del Centro Coordinador en Jamiltepec.

Tanto De la Fuente como Aguirre Beltrán le darán mayor relevancia que Caso a los factores históricos, sociales y económicos, lo que enriquecerá la mirada del contexto nacional para la comprensión de la situación de los indígenas. Aguirre afirmará en sus publicaciones que solo será posible que las culturas indígenas se desarrollen en su propio beneficio en tanto se transformen integralmente, incluyendo a los indios y los ladinos, así como a los mestizos, que forman parte de las mismas comunidades. Lo difícil, como siempre, ha sido el hacer coincidir la mirada académica con las políticas públicas.

A pesar de los debates académicos de la antropología y la historia acerca de las formas de leer la realidad de las comunidades indígenas, el aislamiento de los indígenas permaneció, así como su marginación de las prácticas modernizadoras y la distribución de la riqueza estatal y nacional, preservando su pobreza económica.

Para estos tiempos parte del sector indígena nacional quedaría diluido bajo el concepto de campesino, lo que irá complejizando aún más la comprensión de la problemática social y cultural que enfrentaban. Un gran sector de ellos quedaría incorporado orgánicamente al PRI a través de la Confederación Nacional Campesina, donde en realidad no tenían márgenes de maniobra para desarrollar demandas particulares para la mejora de sus condiciones de trabajo: "Cruelmente, siguieron siendo el "ganado político" del PRI» (Krauze, 2014, p. 212).

La documentación que se fue generando a lo largo de los años en el Centro Coordinador de la Costa la encontramos en los archivos resguardados por el INAH en Yanhuitlán. Ahí se expresa la preocupación por inducir el cambio cultural en las comunidades y promover el desarrollo e integración en las regiones interculturales a la vida económica, social y política de la nación. El camino para lograrlo sería a través de la aculturación en las regiones interculturales, también conocidas como regiones de refugio (CDI, 2012). Se les llevaría educación en el idioma español, la enseñanza de técnicas para la siembra y cuidado de animales, atención médica para prevenir y atender enfermedades, la enseñanza de nuevos oficios.

Aunque fueran sinceros los antropólogos como Aguirre Beltrán o Alonso Fabila en su deseo de ver que se mejorarían las condiciones de vida 
de la gente de la costa, la estrategia sería siempre la de negarlos, negar sus saberes, sus discursos, lo que ellos habrían de decir acerca de sus necesidades y su deseo de preservar muchas de sus tradiciones, que los hacen únicos y auténticos.

El epistemicidio seguirá siendo la forma de configurar las monografías y otros estudios étnicos. Es la forma en que se ha aprendido a construir el relato sobre el otro, negándolo, apenas mirándolo. Para este grupo de profesionistas que he mencionado, al visitar la región de los mixtecos todo en la costa era atraso para ellos. Se necesita ser más críticos con los discursos oficiales y académicos para lograr una descolonización de los saberes. ${ }^{2}$

Cuando comenzaron los trabajos en la zona de la costa, los burócratas e investigadores del INI se enfrentaron a las muchas necesidades que había en la región dado el rezago ancestral. Había problemas básicos que atender en la salud, así como en las situaciones de violencia que irían desencadenándose. Intentaron darles solución a las más de las demandas de apoyo que fueron recibiendo, con recursos escasos, que es otra de las limitantes más

2 Aunque también en estos años Frantz $\mathrm{Fa}$ non estaba escribiendo sus textos críticos sobre los grupos diversos, en su caso el tema eran los negros. frecuentes dentro de estos programas. Pero a pesar de sus contradicciones, los centros coordinadores jugaron un papel humanitario importante, pues llegaron a ser los mejores interlocutores de dichas comunidades.

Los nuevos caminos cambiaron sustancialmente la vida en la región. Primero llegarían las avionetas con los funcionarios, con los años llegarían por terracería camionetas y poco a poco se fueron abriendo caminos, vías de acceso que permitirían la entrada y salida de la gente de las comunidades y sus visitantes. En 1953 trabajaría en ello la Secretaría de Comunicaciones y Obras Públicas, bajo la dirección de Carlos Lazo. Se logrará extender un camino que vincule la Mixteca Alta con la de la costa, en donde estaban los primeros Centros Coordinadores del INI, logrando así algunos de sus primeros objetivos.

Para 1968 se construirá la carretera 200 que corre por la costa oaxaqueña. Las políticas de colonización regionales, en el México de los años cincuenta y sesenta, solo podemos comprenderlas si observamos al INI como un actor principal. Los pueblos indígenas serán comprendidos como culturas diversas, únicas, ancestrales, que viven en un atraso, que a su parecer se superaría incorporándolos al proyecto nacional. Esta mirada del 
proyecto gubernamental se extenderá hasta 1976, siendo reconocida como indigenismo oficial e indigenismo de aculturación e integración. Los caminos, las escuelas, la televisión y las nuevas tecnologías irán generando un acelerado proceso de desindianización, se generarán nuevas identidades que habrán de expresarse también a través de los cambios en su vestimenta y las formas en las que las mixtecas irán viviendo su torso desnudo.

Los académicos continuarán en la reconfiguración de sus paradigmas y para cuando llegue la carretera 200 (1968) ya podrá ser evidente para el pensamiento crítico que los indígenas y el resto de los mexicanos no son tan diferentes entre sí, como lo habían planteado las diversas posturas académicas y políticas de la primera parte del siglo XX. Los mexicanos de las ciudades, además de tener en común rasgos de una fisonomía indígena, tendrán la misma posición de pobreza estructural y falta de oportunidades ante el sistema mexicano dependiente y poco eficiente. «Esto planteó el problema indio bajo una nueva luz. Su posición no se derivaba de su atraso evolutivo sino de su opresión por los sectores dominantes»(Warman, 1978, p. 12).

Vendrán otros investigadores de las ciencias sociales y otras posturas posteriores a los años intermedios del siglo XX, pero ahora no hablaré de ellas, pues voy a detenerme en el momento en el que el Instituto Nacional Indigenista (INI) llega a la costa de Oaxaca con sus Centros Coordinadores, a través del testimonio de las mujeres que vieron cómo sus comunidades irían modificándose.

Las mujeres de las comunidades nos han contado a través de las entrevistas que realizamos que con el Centro Coordinador del INI llegaron los talleres de costura y con ellos la Singer, así como la tela ya elaborada en fábricas, con la que más adelante se coserán los mandiles. Llegaron algunas instructoras y poco a poco algunas mujeres fueron aprendiendo a coser, así como algunos hombres, que incluso ahora tienen el oficio de sastre como don Natalio, quien también nos dio su testimonio.

En el archivo del INI, que se encuentra resguardado en Yanhuitlán, constatamos entre los documentos algunos escritos sobre los talleres, mensajes cotidianos donde se avisa que dejan las llaves del costurero en algún lado y algunas cuentas de gastos. Por lo que queda claro que el mandil llegaría con el proyecto indigenista «integracionista», que se materializaría a través de los Centros Coordinadores del INI. 
La llegada del mandil hemos de comprenderla desde diferentes aspectos. Uno de ellos es la idea de tapar la parte superior del cuerpo de las mixtecas, a quienes encontraron los arqueólogos y curiosos de mediados del siglo $\mathrm{XX}$. Como hemos visto por los testimonios, ellas vivían su desnudez con transparencia, sin que hubiera en su imaginario alguna idea que se asociara a lo incorrecto, provocador o simplemente sexual. Estas ideas llegaron con los indigenistas y visitantes que provenían de las ciudades. La mirada del otro fue lo que empezó a hacer pensar a las mixtecas que debían taparse.

En el testimonio de mi estudiante, que pertenece a Huaxpaltepec, fue muy interesante observar como ella se dio cuenta de la gran distancia que tenía ahora con esta tradición, pues claramente vi su proceso de anagnórisis al afirmar:

He pensado que de no haber ido a la escuela yo estaría vestida con mi pozahuanco y torso desnudo y en este momento esto me parece imposible. Me daría pena mostrar mis pechos, incluso ante mi familia. A veces cuando mi mamá se va a bañar y se quita la blusa, mis hermanos le empiezan a decir que se tape y ella responde que de ahí comieron, que no molesten. A mí a veces me da pena observarla.
Fue un gran cambio para todas las comunidades la llegada de las políticas indigenistas, que se concretaron en proyectos como los del Centro Coordinador del INI. Cuando llegaron estos proyectos a mediados del siglo $\mathrm{XX}$, el Estado mexicano, que se autodenominaría modernizador, estaba en un afán por dejar de ser subdesarrollado y parecerse a los países denominados del primer mundo. Y consideraría que lo atrasado, primitivo, falto de modernidad, sería la situación a atacar, siendo los indígenas y sus culturas la expresión viviente de lo que este Estado no quería para México.

$\mathrm{Al}$ parecer no se comprendería que las relaciones entre los países llamados del primer mundo con los que estarían supuestamente en vías de desarrollo han sido posibles gracias a las ventajas y dinámicas asimétricas que han mantenido con los países colonizados como México. Estos países llamados subdesarrollados han sido parte del juego colonial que permite la preservación de su misma condición desventajosa ante las negociaciones mundiales.

Para el proyecto de modernidad que el Estado quería implementar, la desnudez indígena sería la expresión de lo primitivo, de lo atrasado y de la pobreza. No es de extrañarnos la incomprensión y desentendimiento del 
Estado en relación con la condición indígena. Desde el inicio de la vida colonial se han controlado las expresiones culturales de las comunidades y se han limitado sus capacidades de decisión. Los mixtecos son un pueblo que vivía sin hambre ni pobreza antes de la llegada de los españoles y su empobrecimiento comenzó con las intervenciones de los diversos gobiernos, fueran los virreinales o los del México independiente. La interacción con estos grupos ha sido para beneficio del grupo dominante y la continuidad de las prácticas coloniales, les han negado su diversidad y el despliegue de propuestas propias en equidad. Como afirma Bonfil Batalla

La dinámica histórica puede entenderse como una lucha incesante de los grupos sometidos por conservar y ampliar los ámbitos de su cultura propia (...) frente a los intentos de la sociedad dominante de ampliar y consolidar su propio espectro de control cultural, en función de sus intereses y necesidades (1995, p. 598).

Habrán pasado siglos en los que las comunidades vivieron su desnudez como una forma práctica y sencilla de enfrentar el calor. Con la llegada de la gente de las ciudades la mirada sobre las mujeres mixtecas cambiaría. Bien cae la frase de Jean Paul Sartre de que «la mirada de los otros, es el infierno».
Para la confección de su ropa tradicional ciertamente las mujeres enfrentaban una ardua labor ante lo práctico que resulta el mundo industrializado. Las comunidades sembraban el algodón ${ }^{3}$ y habrían de pasar por todo el proceso de hilado, teñido y tejido para la elaboración de la vestimenta, tanto de mujeres como de hombres, siendo muchas las horas de trabajo invertidas.

Las mujeres mixtecas desde la antigüedad portan el pozahuanco, nombre que deriva del náhuatl cozahuanqui, y se refiere a una falda que tiene rayas. ${ }^{4}$ En mixteco a su falda le llaman che'e. Esta falda tiene como característica que es de algodón y es tejida en un telar de cintura. Es pesada, ya que puede llegar hasta los 700 g., según la cantidad de algodón que lleve este tejido. Se pintan los hilos de diversos colores naturales, como el rojo, que deriva de un animalito que vive en los nopales y se le llama grana cochinilla; el azul, que es vegetal y deriva del palo añil y el púrpura, que se

3 El algodón del Pacífico, Gossypium hirsutum, es originario de Centroamérica y el sur de México. El algodón hirsutum suele ser un algodón blanco, aunque también se desarrolló una variante de color café denominada coyuchi, por el parecido de su color con la piel de coyote.

4 A veces se escribe con $S$ y en otras aparece con Z, siguiendo la denominación náhuatl se empleará la palabra con la ortografía pozahuanco. 
saca de la ordeña del caracol púrpura, que vive en las piedras del Pacífico. Con las madejas ya coloridas se van alternando los hilos en el telar de cintura, de manera que queda un lienzo de rayas horizontales.

La forma de vestir de estas mujeres la encontramos representada desde las pinturas en códices. Esta costumbre de usar una falda enredada y el torso desnudo no solo es de Oaxaca, así mismo se vería en la Huaxteca, o en alguna ciudad maya con condiciones climáticas semejantes. Podemos observar también el uso de huipiles o quechquémitl, con variantes en los diseños.

En esta región costera de Oaxaca durante el siglo XVI serán asignados algunos de los pueblos viejos a don Luis de Castilla, ${ }^{5}$ pariente de Cortés, quien «fue sucedido por su hijo mayor, don Pedro Lorenzo de Castilla, quien muere en 1604» (Gerhard, 1997, pp. 389. 90). Habrá otros pueblos que por sus condiciones de lejanía seguirán siendo gobernados por sus señores indígenas, quienes a partir de entonces dejarán de ser autónomos y estarán sujetos al control de las autoridades españolas, a las que tendrán que darles cuentas. Poca presencia habrá de los curas, pues no hay una gran iglesia, ni conventos, ni monasterios que los hubiera

5 De ahí el nombre actual de Pinotepa de Don Luis. acogido en esta zona. Incluso hasta la actualidad, los curas visitan las comunidades para dar algún servicio.

En las comunidades de nuestro estudio (Mechoacán, Chayuco, Pinotepa de Don Luis y Huaxpaltepec) se usa la palabra chirunda para referirse a la costumbre de la desnudez. Dicen "ella está chirunda», que significa que ella está desnuda o medio desnuda de la parte superior.

En la Enciclopedia del idioma (1988) encontramos una posible raíz en chirusa, que en el español de Argentina se expresa como sinónimo de mujer vulgar, de baja estofa. Una palabra que en Uruguay evolucionó a mozue$l a$. Y en la mixteca oaxaqueña se refiere a una mujer desnuda, pero sin la carga moral de la primera definición. Parece que estamos ante una palabra que llevaron los españoles y que quedó en el lugar, pasando a una descripción neutra. Tal como hemos visto que se mira ahora la desnudez de las mujeres mayores de la región.

En las entrevistas nos cuentan las mujeres que cuando niñas junto con los niños jugaban desnudos, en casa, en el río, en el campo y sus juegos, como los de toda infancia, eran simplemente diversión. El aspecto de la desnudez no era un tema. A las chicas les pondrían obligatoriamente la falda o che'e hasta la adolescencia. 
Hace un par de generaciones todavía era frecuente que las mixtecas se casaran tan jóvenes que durante mucho tiempo se vivió con la idea de que las mujeres empezaban a menstruar cuando se casaban, pensando que el periodo comenzaba por ello. Taparse sus genitales en esta etapa podría responder al despertar de la sexualidad que se avecinaría. El torso desnudo seguiría sin ser un tema: comenzó a serlo hasta la mitad del siglo XX, cuando llegó el INI y los diversos viajeros que explorarían la zona.

Las entrevistadas nos cuentan cómo es que fueron incluyendo el mandil en su vida. A veces fueron los maestros quienes insistieron en que lo usaran, otras veces se menciona a un cura llamado Ramón, quien visitaba el pueblo de Huaxpaltepec, y en otras nos dicen que la mirada de la gente que iba llegando de diversos lados las iría llevando a pensar que deberían usarlo. Las miradas de la gente de fuera por primera vez las hizo sentir incómodas con sus tradiciones.

Poco a poco fueron observando que algunas mujeres iban incluyendo el mandil a su vestir, con mayor frecuencia una vez que ya estaban casadas. Sus vecinas les preguntarían si no sentirían calor, si no les incomodaba, a lo que las otras respondían que no, que una se acostumbraba. Nos contaron que incluso su marido podría ser quien lo cosiera o lo comprara ya hecho para que ellas se lo pusieran. Otras cuentan que al ver que sus vecinas lo iban usando, también ellas decidieron añadirlo a su vida, incluso bordándolo o poniéndole listoncitos o algo que los fuera haciendo más personales.

Mi marido me lo cosía, iba él por la tela y lo hacía para mí, porque yo nunca aprendí a usar esa máquina y él sí, le salía bueno. También hacía otras cosas, a veces para él también. Y como lo cosía pues me lo ponía. Ahora ya lo compro hecho, a veces lo bordamos o así nomás (Sánchez, 1951, Chayuco).

Las formas de vivir el cuerpo, el cubrirlo o no, así como las ideas que se tienen del mismo, son el resultado de la vida en sociedad. A través de la observación de las otras mujeres, sus iguales, se da la imitación y el ejemplo de cómo debe vivirse dentro de la comunidad. Así se va transformando la ética de la presencia y el cambio de su dimensión simbólica, sus valores, así como el lugar en el que se posiciona socialmente a las personas por su vestir.

A principios del siglo XX todas estaban con su pozahuanco, era un símbolo de respeto, como nos han dicho estas mujeres, pero para finales de este siglo eso cambiaría, ahora hay una diversidad de respuestas y expresiones al respecto. 
Fue muy interesante cuando me encontré en mi investigación de campo con una señora de Huaxpaltepec cuando íbamos en el transporte colectivo. No era de mi grupo de entrevistadas, pero me llamó la atención su vestido amarillo comprado en un tianguis. Le pregunté que si ella no usaba a veces su pozahuanco, fuera con mandil o el torso desnudo, a lo que ella respondió: «Yo antes era indita, ahora ya no», lo que habría de entenderse como que antes sí usaba esta ropa. La respuesta fue interesante, porque me dejó ver cómo es que la identidad se configura también a través de la vestimenta. Que el cuerpo es una simbología que se encarna y se asume o no. Que para ellas al dejar el pozahuanco también cambiaría su percepción identitaria y su manera de posicionarse ante su comunidad. Nuestro actuar y vestir está lleno de sentido, solo basta detenernos a observarnos y escucharnos, y a través de esto veremos la manifestación de nuestros valores sociales, que devienen en cierta personalidad.

Sin embargo, aún hoy en día, en el año 2016, encontramos en las comunidades que las mujeres que son monolingües y que son mayores de sesenta años continúan vistiendo con su pozahuanco y chirundas. Son mujeres que no asistieron tampoco a las escuelas y por ello preservaron, además de su lengua, sus formas de vivir, su cuerpo. A estas señoras las vimos con el torso desnudo en casa durante la entrevista, con gran naturalidad y respeto.

Al momento de salir, cuando van al río para bañarse o a alguna otra actividad se ponen encima una capita de algodón corta que a veces deja ver también su pecho, como en la imagen que acompaña este texto. Algunas pueden usar a veces un mandil, porque alguien de la familia se los ha regalado, pero no es la forma diaria de vestir cuando se está en casa.

Las escuelas que fueron llegando a la región ${ }^{6}$ fueron una vía muy importante para introducir en las comunidades el proyecto indigenista «integracionista». Algunas de las mujeres entrevistadas nos relatan en sus testimonios cómo las presionaban de niñas para que se taparan si querían asistir a la escuela, también se les empezaría a presionar para que dejaran de usar su pozahuanco.

Los maestros habían salido de sus propias comunidades a través del reclutamiento de jóvenes que realizaría

6 En las entrevistas mencionan las escuelas a las que asistieron las personas bilingües o ya francamente monolingües, estas se llamaban Benito Juárez, Vicente Guerrero o Cuauhtémoc, nombres que también responden al proyecto nacionalista.

124 Sus cuerpos, nuestras vidas: torso desnudo y mandil... Liliana María Gómez Montes 
Fotografía 1. Mujer mixteca con mandil

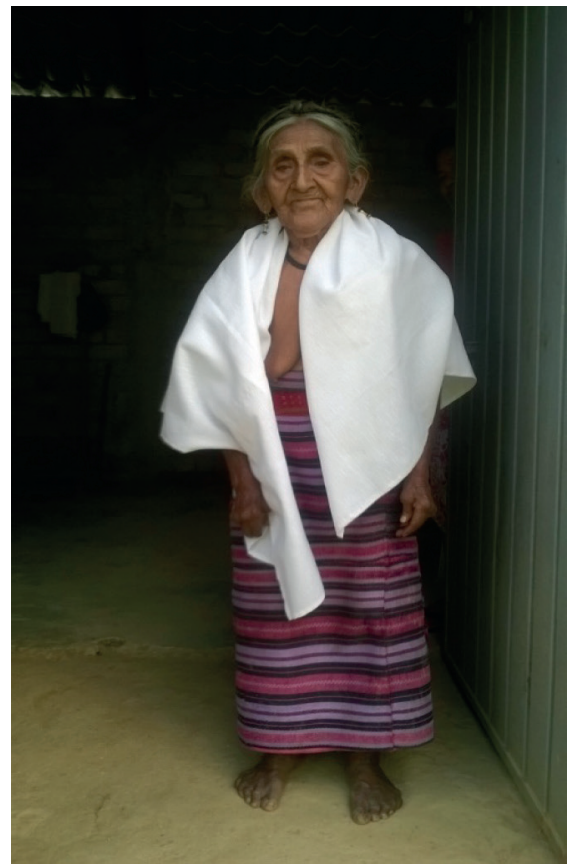

Sra. Teófila Rodríguez, Pinotepa de Don Luis (2015)

el Gobierno para educarlos como profesores, con el fin de que se llevara a través de su propia gente una educación en el idioma castellano y con mentalidad occidental. Ahora las niñas ya no usan el pozahuanco de manera cotidiana para ir a la escuela, y paradójicamente, ahora que han logrado erradicar esta costumbre, las escuelas quieren reintroducirlo como traje de gala para fiestas y eventos escolares, acompañado del mandil.

Es muy claro a través de los relatos de estas mujeres que la condición
Fotografía 2. Mujer mixteca, torso desnudo

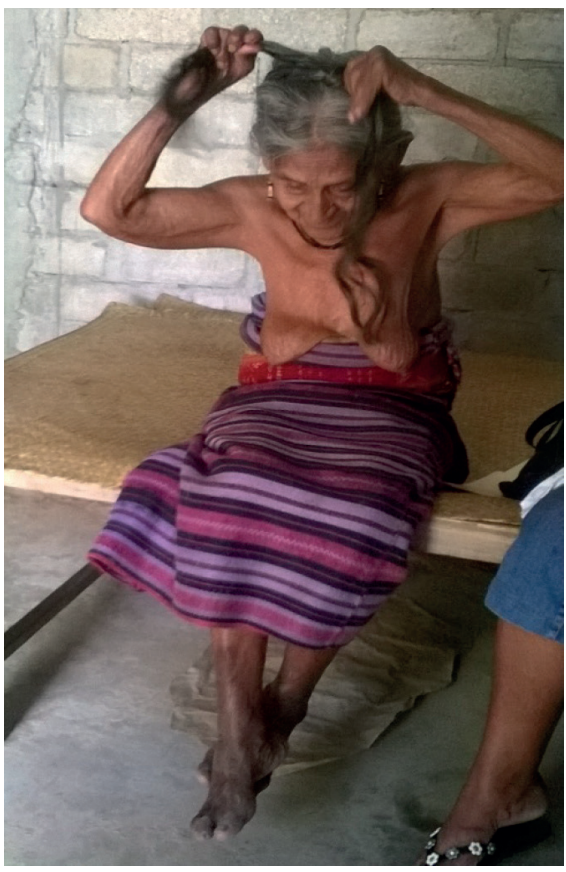

humana es corporal y que el cuerpo es la evidencia material, externa, con la que se expresa nuestro mundo interior, códigos, símbolos o reglas sociales. Que nuestro cuerpo es un vehículo, en el que podemos observar proyectados nuestros códigos compartidos con nuestra comunidad.

En la anécdota de Gutierre Tibón podemos observar la visión de dos mundos encontrándose. La enseñanza o la imitación son las que nos van llevando a adoptar formas de vestir, de ahí el éxito de la moda. Algunas de nuestras 
entrevistadas imitaron a sus vecinas y adoptaron el mandil, otras no, y otras dejaron la ropa hecha en telar de cintura para comprar solo la industrializada. La profesora bilingüe Ynocencia Simón (Huaxpaltepec), quien nos acompañó durante las entrevistas como traductora de la lengua y su cultura, todos los días usaría pantalones hasta la pantorrilla, con blusas compradas en alguna tienda del pueblo.

Fotografía 3. Maestra Ynocencia Simón y Sra. Catalina Plaza.

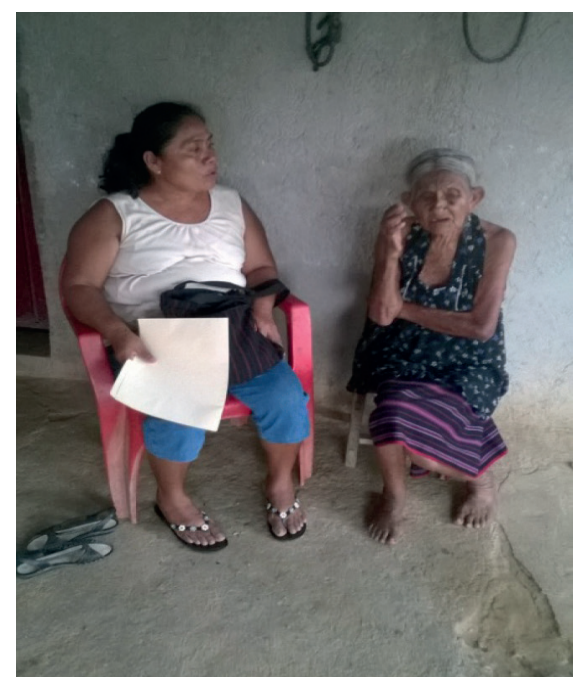

Pinotepa de Don Luis

No puede pasar desapercibido que el mandil, además de cubrir el cuerpo, se trata de una pieza de vestir muy particular, que en sí misma contiene una carga simbólica y nos comunica algo del código social mexicano.
El mandil es la prenda de las trabajadoras de servicio doméstico, mujeres que en las ciudades ocupan una posición baja dentro de la escala de los empleos. Para las mujeres de la mixteca este código urbano es ajeno a su vida si no han visitado las ciudades, como es en la mayor parte de los casos, pero para los trabajadores del INI, quienes lo llevaron, se trata de un código social conocido. Esta propuesta de vestimenta nos lleva a observar una mirada de parte de los Centros Coordinadores del INI frente a las mujeres mixtecas, donde la política integracionista del indigenismo no invitaba a estas mujeres a ocupar un lugar privilegiado dentro de la sociedad mexicana modernizadora. Al contrario, parece una expresión más de discriminación que se materializa en una prenda de vestir. Una política de Estado que niega una oportunidad real de ascenso dentro de la jerarquía social establecida en las ciudades.

Incluso los textiles oaxaqueños que tienen trabajos muy bellos se observan en el mercado mexicano como propios de personas que se encuentran en una escala baja en cuanto a prestigio cultural y condiciones económicas. A menos que estas prendas se saquen de su contexto y se vendan en boutiques de otros países podrán ser valoradas, como sucedió hace meses con unas blusas de diseño mixe que se exponían en Nueva York. 
La mirada se educa conjugando la historia personal con la colectiva. Se configura como un sistema que recibe y devuelve información, es dinámico. Y es la materia a partir de la cual construimos nuestras identidades. Estos códigos que hemos aprendido en sociedad son las pautas con las que nos relacionamos con los otros, así como la base a partir de la que somos nombrados y reconocidos. Nuestro color de piel morena en México sigue siendo una condición a través de la que la discriminación se encarna. Y la ropa podría acentuar tal posicionamiento.

Las jóvenes de las comunidades mixtecas que han ido a la escuela ahora visten jeans, shorts o vestidos comprados en tiendas, tienen celular, miran videos y ya están en el mundo de lo digital, lo que impacta su imaginario de manera definitiva. Sus identidades van en cambio total respecto a las mujeres mayores de su familia. Su percepción actual resuena en su ropa y formas de vivir el cuerpo. Conceden vestirse con pozahuanco y mandil para ciertas fiestas familiares, porque son sus familias quienes así se los piden.

Las mujeres adultas que entrevistamos y tienen el mandil integrado de manera cotidiana nos han dicho que para ellas son prendas bonitas, que les gustan porque es su tradición y la aprecian. Las madres nos han dicho que les gustaría que sus hijas lo usaran más seguido, pero comprenden y respetan que el mundo ha cambiado y que sus jóvenes se enfrentan a nuevos retos. Ellas saben que la lengua indígena y la ropa han sido marcas para la discriminación, y han reconocido que por ello no insisten con la ropa, así como tampoco enseñaron a sus hijas a hablar en mixteco, las más de las veces, durante su niñez.

A través de las entrevistas hemos podido observar cómo se plasma la historia de México en el cuerpo de sus mujeres. Podemos ver en su experiencia corporal la traducción o materialización de una política de Estado, indigenista, integracionista, para la que lo indígena ha sido un problema. Las mujeres mixtecas actualmente viven un cambio acelerado en sus identidades y expresiones corporales, tal como la tecnología va cambiando nuestro mundo contemporáneo en todas partes. La huella de la innovación tecnológica y las políticas del Estado mexicano han dejado una huella cultural y textil. Inevitablemente nos encontramos inmersas en la dinámica de la experiencia sensible del mundo y de nuestro cuerpo que se re-significa, materializándose en nuestras identidades, en nuestra posición y comprensión del mundo. 


\section{Referencias}

Alonso, M. (1988). Enciclopedia del idioma (vol. I, A-CH). México: Aguilar.

Archivo del Centro Coordinador del Instituto Nacional Indigenista (INI) de Jamiltepec (1954-2000). Consultado en INAH/Yanhuitlán, 2015.

Bonfil, G. (1995). Obras escogidas (tomo 2). Instituto Nacional Indigenista (INI) e Instituto Nacional de Antropología e Historia (INAH), México.

Drucker, S. (1963). Cambio de indumentaria. La estructura social y el abandono de la vestimenta indigena en la villa de Santiago Jamiltepec. Instituto Nacional Indigenista, México.
Fabila, A. (2010). Mixtecos de la costa. Estudio etnográfico de Alfonso Fabila en Jamiltepec Oaxaca. México: CDI, Serie Pioneros del Indigenismo en México.

Gerhard, P. (Enero-marzo, 1997). Congregaciones de indios en la Nueva España antes de 1570 . Historia Mexicana, 26(23), 347-388.

Krauze, E. (2014). La presidencia imperial de Manuel Ávila Camacho a Carlos Salinas de Gortari. México: Tusquets.

Tibón, G. (1961). Pinotepa Nacional. Mixtecos, negros y triques. Universidad Nacional Autónoma de México.

Warman, A. (1978). Indios y naciones del indigenismo. Recuperado de http://www. catedrawarman.org/articulos/1978_ indios_naciones_indigenismo.pdf 